\title{
Bis-indole derivatives with antitumor activity turn out to be specific ligands of human telomeric G-quadruplex
}

\section{Jussara Amato ${ }^{1}$, Nunzia laccarino ${ }^{1}$, Bruno Pagano ${ }^{1}$, Rita Morigi ${ }^{2}$, Alessandra Locatelli ${ }^{2}$, Alberto Leoni ${ }^{2}$, Mirella Rambaldi ${ }^{2}$, Pasquale Zizza ${ }^{3}$, Annamaria Biroccio ${ }^{3}$, Ettore Novellino ${ }^{1}$ and Antonio Randazzo ${ }^{1 *}$}

1 Department of Pharmacy, University of Naples "Federico II", Naples, Italy

2 Department of Pharmacy and Biotechnology (FaBiT), University of Bologna, Bologna, Italy

${ }^{3}$ Experimental Chemotherapy Laboratory, Regina Elena National Cancer Institute, Rome, Italy

\section{Edited by:}

Asier Unciti-Broceta, The University of Edinburgh, UK

Reviewed by:

Marc Vendrell, University of

Edinburgh, UK

Juan Jose Diaz-Mochon,

Universidad de Granada, Spain

*Correspondence:

Antonio Randazzo, Department of

Pharmacy, University of Naples

"Federico II," Via D. Montesano 49,

Napoli, 80131, Italy

e-mail: antonio.randazzo@unina.it
Bis-indolinone derivatives having either 2,6-disubstituted pyridine core (1a and $\mathbf{1 b}$ ) or 1,10-disubstituted phenanthroline core $(\mathbf{2} \mathbf{a}$ and $\mathbf{2} \mathbf{b})$, already known to have antitumor activity, have been tested as potential G-quadruplex binders. Compounds $\mathbf{2 a}$ and $\mathbf{2} \mathbf{b}$ are able to selectively stabilize G-quadruplex over duplex DNA, and also to discriminate among different G-quadruplex structures, having a particular affinity for the parallel form of the human telomeric G-quadruplex. Both compounds are also able to induce telomeric DNA damage that may explain the activity of these compounds.

Keywords: G-quadruplex, anticancer activity, telomeric damage, thermal stabilization, phenanthroline derivatives, pyridine derivatives

\section{INTRODUCTION}

G-quadruplexes (G4) are four-stranded nucleic acid structures that spontaneously form within G-rich sequences of DNA and RNA in the presence of cations (Bochman et al., 2012). The recent unambiguous evidence of G4 formation in living cells has increased the enthusiasm and has propelled numerous investigations in this field (Biffi et al., 2013). Several experiments have located G4-forming sequences in different critical positions of the human genome, mainly at the telomeric and gene promoter level (Bochman et al., 2012). In particular, the telomeric regions at the chromosome ends play a critical role in the regulation of cellular proliferation. They are made up by $2-20 \mathrm{~kb}$ of double-stranded TTAGGG repeats and feature a $3^{\prime}$ singlestranded overhang of 50-500 nucleotides (Wright et al., 1997). Parallel to normal cells proliferation, telomeres get gradually shorter, triggering irreversible cellular growth arrest (senescence) (Harley et al., 1990; Price, 1999). A telomere maintenance mechanism is provided by the six-membered protein complex called shelterin and by telomerase. The latter adds copies of the repeated motif to the end of the single-stranded overhang. This enzyme is transcriptionally repressed in most differentiated human somatic cells while being overexpressed in about $85 \%$ of cancer cells (Kim, 1997; Shay and Wright, 2005). In the remaining $15 \%$ of human tumors, telomere lengthening is obtained by a different mechanism known as alternative lengthening of telomere (ALT) (Fajkus et al., 2005). In both cases, telomeres are maintained to a stable length with consequent senescence circumvention and cellular immortalization. It has been shown that the $3^{\prime}$ G-rich singlestranded overhang of the human telomeric DNA can adopt G4 structures and that the formation of the G-quadruplexes inhibits telomerase activity in vitro (Zahler et al., 1991). Furthermore, it has also been demonstrated that molecules that stabilize telomeric G-quadruplexes increase the inhibition of the telomerase (Sun et al., 1997) and lead to telomeric protein uncapping, which, in turn, leads to the onset of DNA damage responses and cellular apoptosis. This has opened a new drug intervention field in anticancer therapy. Several different classes of ligands that target G4 DNA have been developed (Granzhan et al., 2010; Monchaud et al., 2010; Ohnmacht and Neidle, 2014). A number of these have been identified by our research group and most of them were discovered in order to target the grooves of the G4 structures (Cosconati et al., 2009, 2010, 2012; Pagano et al., 2010; Petraccone et al., 2011; Di Leva et al., 2013). On the other hand, several other research groups have developed molecules characterized by an extended planar aromatic scaffold, which is generally able to stack on the external G-tetrads of the G4. Compounds having a central pyridine (like, for example, pyridostatin and 360A) (Granotier et al., 2005; Rodriguez et al., 2008) or 1,10-phenanthroline (like, for example, PhenDC3, and PhenDC6) moieties (Dhamodharan et al., 2012) belong to this latter group.

Recently, some of us have synthesized and successfully tested very similar molecules as antitumor agents: the bis-indolinone derivatives with the 2,6-disubstituted pyridine core ( $\mathbf{l a}$ and $\mathbf{1 b}$ ) as well as the same derivatives with the 1,10-disubstituted phenanthroline core (2a and 2b) (Figure 1) (Andreani et al., 2008, 2010). Interestingly, the structural similarities of these compounds with the mentioned G4 binders inspired us a further investigation in order to evaluate the G4 binding properties of $\mathbf{1} \mathbf{a}, \mathbf{b}$ and $\mathbf{2} \mathbf{a}, \mathbf{b}$, and possibly to propose a potential mode of action of these derivatives capable to explain their antitumor activity. In particular, in this paper we report the results of the binding studies of compounds 
<smiles></smiles><smiles>[R7]c1ccc2c(c1[R])/C(=C/c1ccc3ccc4ccc(/C=C5/C(=O)Nc6ccc([R])c([R])c65)nc4c3n1)C(=O)N2</smiles>

2a $\quad \mathrm{R}_{1}=\mathrm{OMe} \quad \mathrm{R}_{2}=\mathrm{H}$

2b $\quad \mathrm{R}_{1}=\mathrm{H} \quad \mathrm{R}_{2}=\mathrm{Cl}$

FIGURE $\mathbf{1}$ | Chemical structures. Chemical structures of compounds $\mathbf{1} \mathbf{a}, \mathbf{b}$ and $\mathbf{2} \mathbf{a}, \mathbf{b}$.

$\mathbf{1 a}, \mathbf{b}$ and $\mathbf{2 a}, \mathbf{b}$ with different G-quadruplex topologies, along with their capability to induce telomeric damage.

\section{MATERIALS AND METHODS OLIGONUCLEOTIDES}

All synthetic oligonucleotides have been purchased by Biomers (Germany), purified employing standard HPLC protocols and checked for their integrity by MALDI mass spectrometry. In particular, the following DNA sequences have been used for the experiments: two different truncations of human telomeric DNA sequence, namely $5^{\prime}$-TAGGGTTAGGGTTAGGGTTAGGG$3^{\prime}$ (tel23) and $5^{\prime}$-TTAGGGTTAGGGTTAGGGTTAGGGTT- $3^{\prime}$ (tel26); two sequences from the promoter region of the $c$-kit oncogene, namely $5^{\prime}$-AGGGAGGGCGCTGGGAGGAGGG$3^{\prime}$ (ckit1) and 5'-CGGGCGGGCGCGAGGGAGGGG-3' (ckit2); the self-complementary duplex-forming Dickerson dodecamer $5^{\prime}$-CGCGAATTCGCG-3' (ds12).

\section{PREPARATION OF THE SAMPLE}

G-quadruplexes were prepared in the appropriate buffer $(10 \mathrm{mM}$ $\mathrm{Li}_{3} \mathrm{PO}_{4}, 50 \mathrm{mM} \mathrm{KCl}, \mathrm{pH} 7.0$ for ckit2; $10 \mathrm{mM} \mathrm{Li}_{3} \mathrm{PO}_{4}, 100 \mathrm{mM}$ $\mathrm{KCl}, \mathrm{pH} 7.0$ for all the other oligonucleotides) at $10 \mu \mathrm{M}$ single strand concentration, unless otherwise stated. The solutions have been annealed by heating at $90^{\circ} \mathrm{C}$ for $5 \mathrm{~min}$, and gradually cooling to room temperature overnight. The concentration of all oligonucleotides was measured at $260 \mathrm{~nm}$ by UV measurement at $90^{\circ} \mathrm{C}$ using the appropriate molar extinction coefficients. Parallel arrangement of tel23 oligonucleotide was obtained as reported in the literature (Renciuk et al., 2009), by annealing of $10 \mathrm{mM}$ single strand oligonucleotide in $10 \mathrm{mM} \mathrm{Li}_{3} \mathrm{PO}_{4}, 100 \mathrm{mM} \mathrm{KCl}, \mathrm{pH}$
7.0. After annealing, the concentrated DNA solution was kept at $4^{\circ} \mathrm{C}$ for $24 \mathrm{~h}$ before dilution. After dilution (necessary for spectroscopic measurements), the concentration of the sample was refined by measuring absorption at $260 \mathrm{~nm}$, using a molar extinction coefficient appropriate for these conditions. To verify that the dilution did not alter the species in solution, $\mathrm{CD}$ spectral changes with time were checked, without any appreciable change observed over the period of time required to complete the experiments.

\section{CIRCULAR DICHROISM (CD) SPECTROSCOPY}

CD spectra and CD melting curves of oligonucleotides were recorded on a Jasco J-715 spectropolarimeter equipped with a Jasco PTC-423S Peltier temperature controller. CD spectra were recorded in the wavelength range $230-360 \mathrm{~nm}$ at $20^{\circ} \mathrm{C}$, with a scan rate of $100 \mathrm{~nm} / \mathrm{min}$, a response time of $1 \mathrm{~s}$ and a bandwidth of $1 \mathrm{~nm}$. All the spectra were averaged over 3 scans. Buffer baseline was subtracted from each spectrum. The DNA concentration was $10 \mu \mathrm{M}$ (as single strand) and ligand stock solution was $1.5 \mathrm{mM}$ in DMSO. DNA/ligand mixtures were obtained by adding 4 molar equiv. of ligands $(40 \mu \mathrm{M})$. CD melting were performed in the temperature range $20-100^{\circ} \mathrm{C}$, at the heating rate of $1^{\circ} \mathrm{C} / \mathrm{min}$ by following changes of the $\mathrm{CD}$ signal at the wavelengths of maximum variations upon oligonucleotide folding. The melting temperatures were determined from fit of melting curves using two state transition model implemented in Origin 8.0 program. Each melting experiment was performed at least three times.

\section{GEL ELECTROPHORESIS}

Native gel electrophoresis analysis was carried out on $15 \%$ polyacrylamide gel at $5^{\circ} \mathrm{C}$, which was run in $1 \times \mathrm{TB}(\mathrm{pH}$ 7.5) buffer supplemented with $50 \mathrm{mM} \mathrm{KCl}$. An oligonucleotide concentration of $50 \mu \mathrm{M}$ was used for each sample. Various amounts (2-4 equiv) of ligands $\mathbf{1 a}, \mathbf{b}$ and $\mathbf{2 a}, \mathbf{b}$ were incubated with DNA at $25^{\circ} \mathrm{C}$ for $1 \mathrm{~h}$ before loading. Prior to loading the mixtures onto the gel, $1 \mu \mathrm{L}$ of glycerol solution $(60 \% \mathrm{v} / \mathrm{v})$ was added. The total volume loaded in each well was $10 \mu \mathrm{L}$.

\section{MOLECULAR DOCKING}

The crystal structure of the 23-mer human telomeric Gquadruplex DNA 5'-TAGGGTTAGGGTTAGGGTTAGGG-3' bound to a tetra-substituted naphthalene diimide ligand ( $\mathrm{PDB}$ code $3 \mathrm{CDM}$ ) was used as the target for docking studies (Parkinson et al., 2008). The ligand was removed from the structure to leave empty binding sites. The parallel topology of the structure results in accessible external $5^{\prime}$ and $3^{\prime}$ planar G-tetrad surfaces, defined as the grid box, being the potential binding sites for the ligands. The size of the box was constrained to $15 \times 15 \times$ $15 \AA$ in the $\mathrm{x}, \mathrm{y}$, and $\mathrm{z}$ dimensions. After optimizing the ligands and assigning partial atomic charges, docking calculations were performed with AutoDock4.0 program using Lamarckian genetic algorithm (Morris et al., 2009). Grid maps were generated for each atom type in the ligand using AutoGrid. An active site box was created with a grid spacing of $0.375 \AA$. The maximum number of energy evaluations was set to $1.0 \times 10^{6}$, the maximum number of genetic algorithm operations was set to $2.7 \times 10^{4}$, the number of individuals in population was set to 150 , the rate 
of mutation and crossover were set to 0.02 and 0.8 , respectively. When searching the conformational and orientational spaces of a ligand with rotatable bonds having full flexibility, the structure of the G-quadruplex was kept rigid. 20 independent dockings were carried out to evaluated different ligand poses.

\section{CELLS AND CULTURE CONDITIONS}

BJ fibroblasts expressing hTERT plus SV40 early region (BJHELT) were obtained as previously reported (Salvati et al., 2010). The cell line was grown in Dulbecco Modified Eagle Medium (DMEM, Invitrogen Carlsbad, CA, USA) supplemented with 10\% fetal calf serum, $2 \mathrm{mM}$ L-glutamin and antibiotics.

\section{IMMUNOFLUORESCENCE}

Immunofluorescence (IF) was performed as previously described (Salvati et al., 2007). Briefly, cells were fixed in 2\% formaldehyde and permeabilized in PBS plus $0.25 \%$ Triton X-100 for $5 \mathrm{~min}$ at room temperature. For immunolabeling, cells were incubated with primary antibody for $2 \mathrm{~h}$ at room temperature, washed twice in PBS and finally incubated with the secondary antibodies for $1 \mathrm{~h}$. The following antibodies were used: rabbit policlonal anti-TRF1 antibody (Abcam Ltd.; Cambridge UK); mouse monoclonal anti- $\gamma \mathrm{H} 2 \mathrm{AX}$ antibody (Upstate, Lake Placid, NY); TRITCconjugated Goat anti-Rabbit, FITC-conjugated Goat anti Mouse (Jackson Immunoresearch, Suffolk, UK). Nuclei were immunostained with DAPI. Fluorescence signals were recorded by using a Leica DMIRE2 microscope equipped with a Leica DFC 350FX camera and elaborated by Leica FW4000 deconvolution software (Leica, Solms, Germany). For quantitative analysis of $\gamma \mathrm{H} 2 \mathrm{AX}$ positivity, 200 cells on triplicate slices were scored. For TIF analysis, a single plane was analyzed and $30 \gamma \mathrm{H} 2 \mathrm{AX}$-positive cells were scored. Cells with at least 4 co-localizations $(\gamma \mathrm{H} 2 \mathrm{AX} / \mathrm{TRF} 1)$ were considered as TIF-positive.

\section{STATISTICAL ANALYSIS}

The biological experiments have been repeated three times and the obtained results are presented as means \pm standard deviation (SD). Significant changes were assessed by using Student's $t$-test for unpaired data, and $P$-values $<0.05(*)$ were considered significant.

\section{RESULTS AND DISCUSSION TARGET SELECTION}

In order to investigate the G-quadruplex binding properties of compounds $\mathbf{1} \mathbf{a}, \mathbf{b}$ and $\mathbf{2 a} \mathbf{a} \mathbf{b}$ (Figure 1), a number of G-quadruplex forming sequences were selected for this investigation. In particular, we focused our attention on both telomeric and nontelomeric sequences able to form G-quadruplexes and having different folding topologies.

As far as telomeric DNA is concerned, it is well known that, in the presence of $\mathrm{K}^{+}$, it can fold into a variety of G-quadruplex topologies depending on experimental conditions and length of the sequences (Dai et al., 2008). Since this can have important implications in drug discovery, we selected telomeric DNA truncations and experimental conditions such as to have three different folding topologies, which possess most of the structural features of numerous folding topologies of telomeric DNA. Thus, we considered two different truncations of human telomeric DNA sequence, namely tel23 and tel26 (Material and Methods). Vorlickova and co-workers have demonstrated that a high DNA concentration promotes the G4 parallel folding of human telomeric sequence (Renciuk et al., 2009) and that, although intermolecular species may be formed at high concentrations, the majority of oligonucleotides form intramolecular G4 structures. Thus, we prepared a couple of sample of tel23 that were structured at "low concentration" $(10 \mu \mathrm{M})$ and "high concentration" (10 mM) conditions, respectively. Particularly, at "low concentration" conditions, tel23 is expected to form the so-called hybrid 1 G4 structure (Figure 2) (hereafter referred to as tel23-h), whereas, at "high concentration" conditions, the tel 23 is expected to fold into a G4 parallel structure (hereafter referred to as tel23p). On the other hand, the sequence tel26 at $10 \mu \mathrm{M}$ is expected to fold into the hybrid 2 G4 structure (Figure 2). In order to verify that these sequences actually adopt the expected folding, CD experiments were performed. Indeed, CD is a well-established technique for determining the presence and the overall topologies

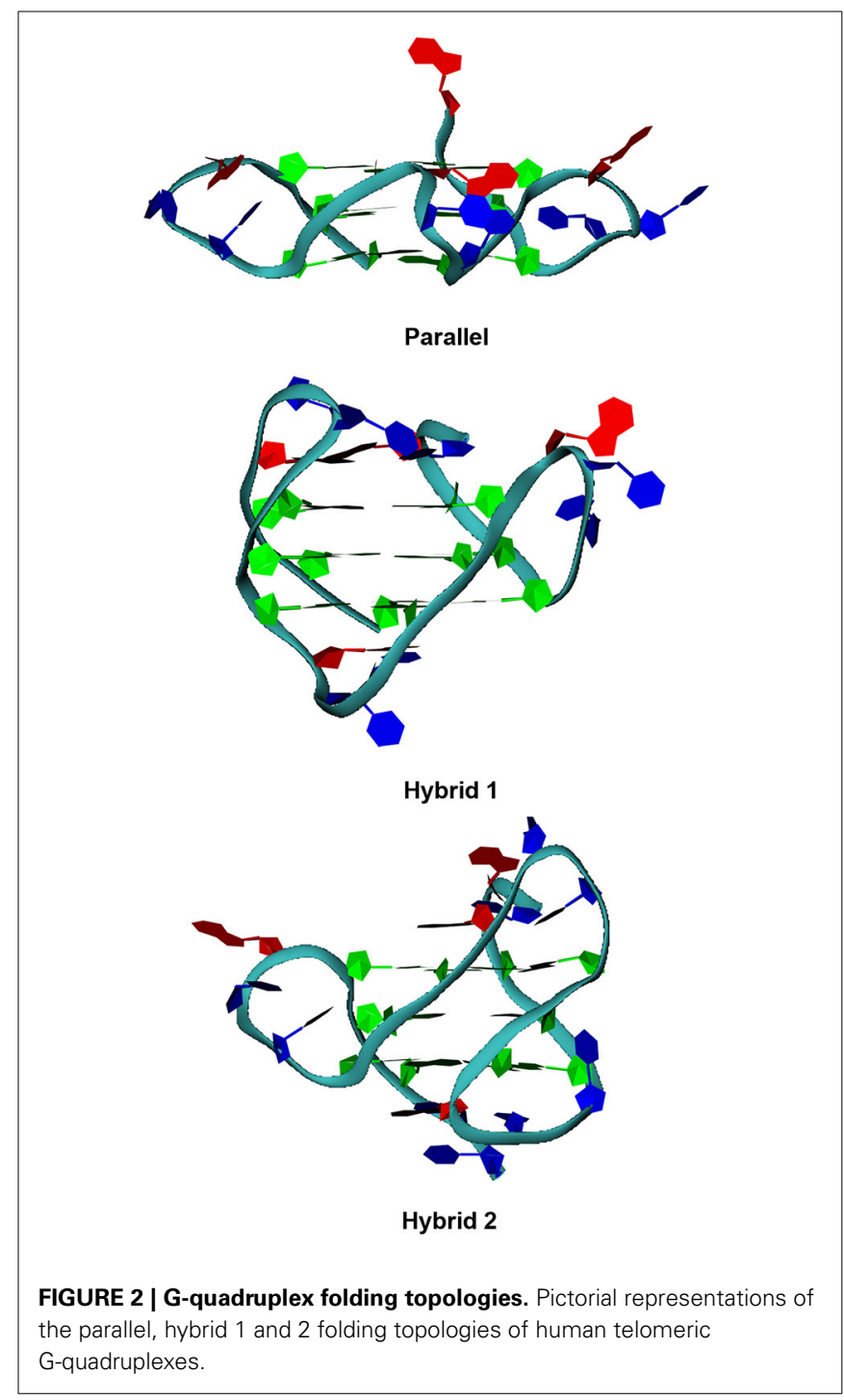


of G4 structures (Masiero et al., 2010; Karsisiotis et al., 2011; Randazzo et al., 2013), although it should be noted that the interpretation of CD spectra requires spectra of well characterized G4 structures for comparison. The tel26 sequence showed a CD spectrum having two positive bands at 290 and $268 \mathrm{~nm}$, and a weak negative band at around $240 \mathrm{~nm}$ (Figure S1, Supplementary Material). These data are consistent with a hybrid 2 G4 folding topology. Very similar CD spectrum was obtained for tel23-h, indicating also in this case an antiparallel G4 folding topology (namely hybrid 1) (Figure S1, Supplementary Material). Tel23-p actually adopts a parallel conformation, having positive band around $265 \mathrm{~nm}$ and a negative band around $240 \mathrm{~nm}$ in the CD spectrum (Figure S1, Supplementary Material).

As mentioned above, we also took into consideration two non-telomeric sequences (see Materials and Methods) and both of them were analyzed by CD spectroscopy. Particularly, we prepared the promoter DNA sequence ckit1, which exists as a parallel structure (Phan et al., 2007), having a characteristic positive band at $262 \mathrm{~nm}$ and a negative band at $240 \mathrm{~nm}$ in the CD spectrum (Figure S1, Supplementary Material). The other target G-quadruplex considered is that formed by the ckit2 sequence, that exists in a dimeric parallel-stranded conformation (Kuryavyi et al., 2010) as indicated by a major positive band at $262 \mathrm{~nm}$ and a negative band at $240 \mathrm{~nm}$.

Finally, in order to evaluate the selectivity of the ligands for the G4 over the duplex DNA, we used as target also the Dickerson duplex-forming dodecamer (ds12).

\section{BINDING ANALYSIS}

Circular dichroism (CD) studies were performed to explore the potential of the new ligands to alter the native folding topology of the investigated G-quadruplexes, inducing a particular conformation. Thus, the bis-indolinone derivatives with the 2,6disubstituted pyridine core $(\mathbf{1} \mathbf{a}, \mathbf{b})$, as well as the derivatives with the 1,10-disubstituted phenanthroline core (2a,b) were synthesized as previously described (Andreani et al., 2008, 2010). Upon addition of an excess of ligands (4 equivalents relative to the DNA), no relevant variations of DNA chiroptical signal were observed for all the analyzed structures (Figure S1, Supplementary Material), thus suggesting an overall conservation of the G4 structures as well as of their architectures. Analogously, the interaction between the ligands and the Dickerson duplexforming dodecamer (ds12) was also investigated by CD spectroscopy to evaluate their effect on the reference DNA duplex. The
CD spectra of ds12 in the absence and in presence of ligands in solution were almost superimposable (Figure S1, Supplementary Material), thus suggesting that the investigated compounds do not alter the duplex structure.

Then, the DNA-stabilizing properties of the compounds were evaluated by measuring the ligand-induced change in the melting temperature $\left(\Delta T_{m}\right)$ of the various $\mathrm{G} 4$-forming sequences as well as of the duplex-forming sequence in $\mathrm{CD}$ melting experiments (Giancola and Pagano, 2013). All the thermal denaturations were monitored at the wavelengths of maximum CD intensity. In particular, the melting profiles of the parallel G4 structures were recorded at $264 \mathrm{~nm}$ (tel23-p) and $262 \mathrm{~nm}$ (ckit1, ckit2), while the thermal denaturations of the hybrid-type G4s were monitored at $289 \mathrm{~nm}$ (tel23-h) and $290 \mathrm{~nm}$ (tel26) (Figure S2, Supplementary Material). Instead, CD melting curves of ds12 duplex were recorded at $280 \mathrm{~nm}$. Ligands $\mathbf{1 a}$ and $\mathbf{1 b}$ did not increase significantly the stability of any G4 DNAs as well as of duplex (Table 1). On the other hand, ligands $\mathbf{2 a}$ and $\mathbf{2 b}$ enhanced the stability of the parallel telomeric G4 tel23-p by 5.5 and $15.5^{\circ} \mathrm{C}$, respectively (Figure 3 and Table 1). Very interestingly, the same ligands showed to induce only a slight increase (up to $3.0^{\circ} \mathrm{C}$ ) of thermal stability of all the other investigated G4s and none for the duplex. These results highlight the fact that ligands $\mathbf{2 a}$ and

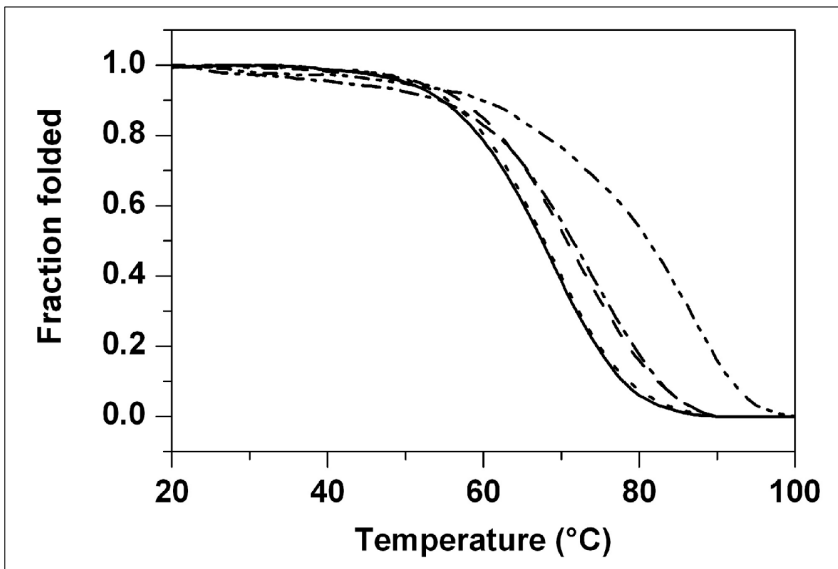

FIGURE 3 | CD melting experiments. Normalized CD melting curves of tel23-p in the absence (solid) and in presence of 4 molar equiv of ligands $\mathbf{1 a}$ (dash), $\mathbf{1 b}$ (dot), $\mathbf{2 a}$ (dash dot), and $\mathbf{2 b}$ (dash dot dot). $T_{m}$ values are listed in Table 1.

Table 1 | Melting temperatures.

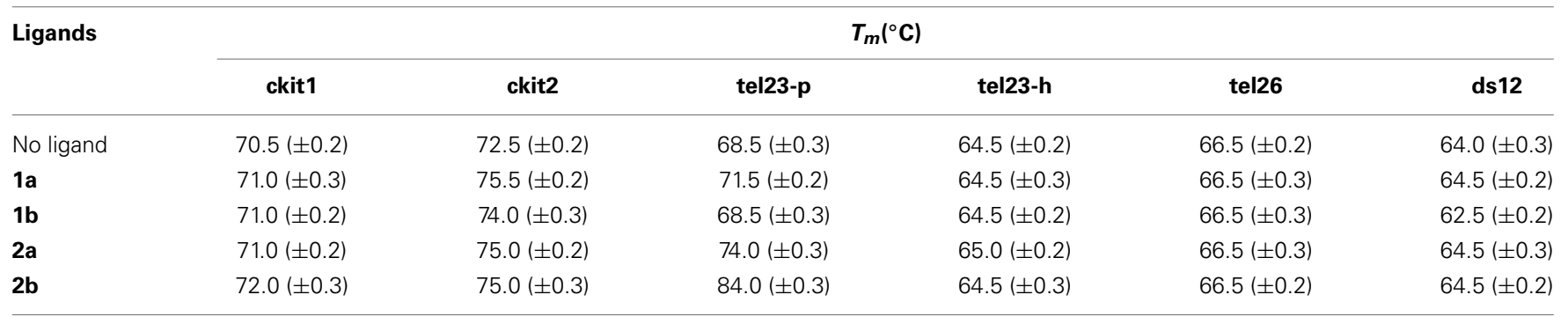

Melting temperatures of G-quadruplex and duplex DNAs with and without ligands measured by CD melting experiments. 


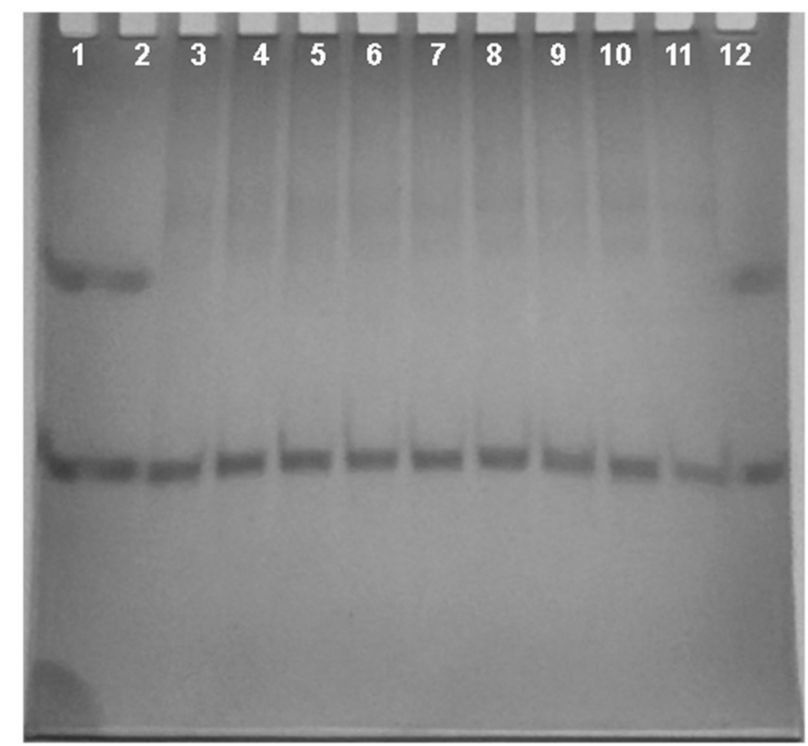

FIGURE 4 | Nondenaturing PAGE. Nondenaturing PAGE of human telomeric DNA tel23-p $(50 \mu \mathrm{M})$ with increasing equivalents of ligands (2 and 4 eq.) at $5^{\circ} \mathrm{C}$. Lanes 1 and 2: bromophenol blue; lane 3: tel23-p alone; lane 4: [tel23-p+1a] 1:2 mixture; lane 5: [tel23-p+1a] 1:4 mixture; lane 6: [tel23-p+1b] 1:2 mixture; lane 7: [tel23-p+1b] 1:4 mixture; lane 8: [tel23-p+2a] 1:2 mixture; lane 9: [tel23-p+2a] 1:4 mixture; lane 10: [tel23-p+2b] 1:2 mixture; lane 11: [tel23-p+2b] 1:4 mixture; lane 12: bromophenol blue.

2b not only selectively stabilize G4 over duplex DNA, but also discriminate among different G-quadruplex structures.

Nondenaturing gel electrophoresis experiments were performed on tel23-p, that is the G-quadruplex more stabilized by the ligands. In particular, the experiments were performed before and after the addition of the ligands, to confirm the presence of the intramolecular G4 structure as major conformation in solution. As shown in Figure 4, tel23-p moves essentially as single band in the gel, thus suggesting the absence of high-order structures. Moreover, the addiction of ligands did not have any pronounced effect on the G4 mobility. This clearly indicates that (i) all investigated ligands do not induce DNA dimerization/oligomerization, (ii) in agreement with $\mathrm{CD}$ results these ligands do not promote any G4 conformational change.

\section{BIOLOGICAL AND MOLECULAR ACTIVITY}

The two molecules that were able to significantly increase the thermal stability of the telomeric G4 were further investigated from biological point of view. In particular, we evaluated if the mechanism through which the two bis-indole derivatives $\mathbf{2 a}$ and $\mathbf{2 b}$ exert their antitumor activity is due to their ability to bind the G4 DNA structures. Thus, human transformed fibroblasts (BJEHLT) were exposed for $24 \mathrm{~h}$ to different concentrations of the two compounds and activation of DNA damage response (DDR) was evaluated by immunofluorescence. As shown in Figure 5, both ligands, even if at different extents, induced the phosphorylation of $\mathrm{H} 2 \mathrm{AX}$, a hallmark of DDR at almost all the drug doses tested (Thiriet and Hayes, 2005). Specifically, treatment
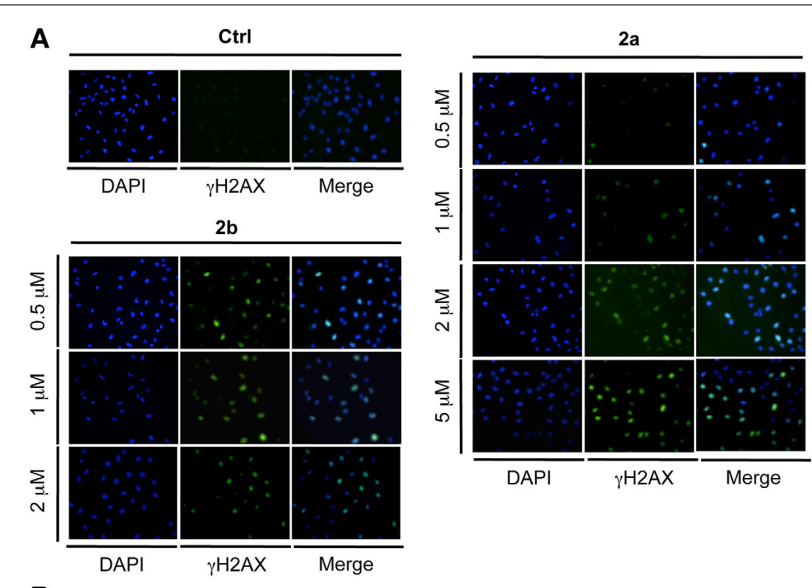

B

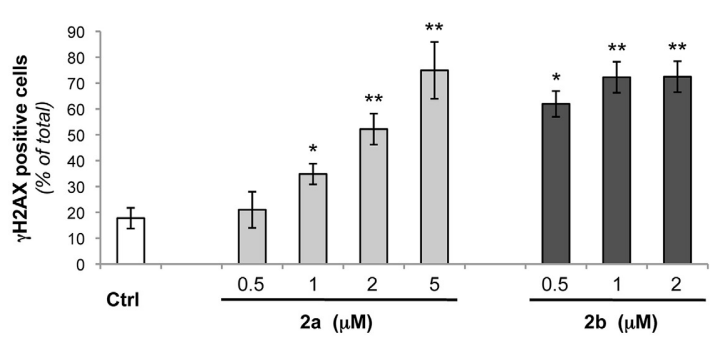

FIGURE 5 | Analysis of DNA damage response by bis-indole derivatives $\mathbf{2 a}$ and $\mathbf{2 b}$. Transformed BJ-EHLT fibroblasts were grown for $24 \mathrm{~h}$ in absence (-) or in presence of the indicated concentrations of compound $\mathbf{2 a}$ or $\mathbf{2 b}$. DNA damage response was evaluated by immunofluorescence (IF) analysis by using an anti- $\gamma \mathrm{H} 2 \mathrm{AX}$ antibody (green) and DAPI (blue) was used to mark nuclei. (A) Representative images of IF analysis. Images were acquired by using a Leica Deconvolution microscope (magnification 20x). (B) Quantification of $\gamma \mathrm{H} 2 \mathrm{AX}$-positive BJ-EHLT fibroblasto from (A). Histograms show the mean values $\pm S D$ of at least three independent experiments. $p$-values were calculated using the student $t$-test $\left(^{*} p<0.05\right.$; $* * p<0.005)$.

with compound 2a produced a dose-dependent effect with an induction of $\gamma \mathrm{H} 2 \mathrm{AX}$-positive cells starting from $1 \mu \mathrm{M}$ (about $30 \%$ ) and reaching about $70 \%$ of positive cells at $5 \mu \mathrm{M}$ concentration (Figure 5). Interestingly, exposure of BJ-EHLT to $0.5 \mu \mathrm{M}$ of $\mathbf{2} \mathbf{b}$ was already sufficient to induce a potent phosphorylation of $\mathrm{H} 2 \mathrm{AX}$ (more than $50 \%$ of positive cells), percentage that does not further enhanced with the increase of the dosage (Figure 5). Altogether, these results suggest that the chemical substituents introduced in the tested molecules can determine a different affinity of the two ligands for the target.

To evaluate whether $\gamma \mathrm{H} 2 \mathrm{AX}$ was phosphorylated in response to dysfunctional telomeres, the most effective drug concentrations of both compounds were tested by double immunofluorescence (IF). The analysis performed by deconvolution microscopy revealed that both compounds induced $\gamma \mathrm{H} 2 \mathrm{AX}$ foci that colocalized with TRF1, an effective marker for telomeres, generating the so-called telomere-dysfunction induced foci (TIFs) (Takai et al., 2003) (Figure 6), clearly indicating that the tested compounds caused telomere localized damage. Consistent with these data, results from quantitative analysis revealed that both 2 a and $\mathbf{2 b}$ significantly increased the percentage of cells with more 


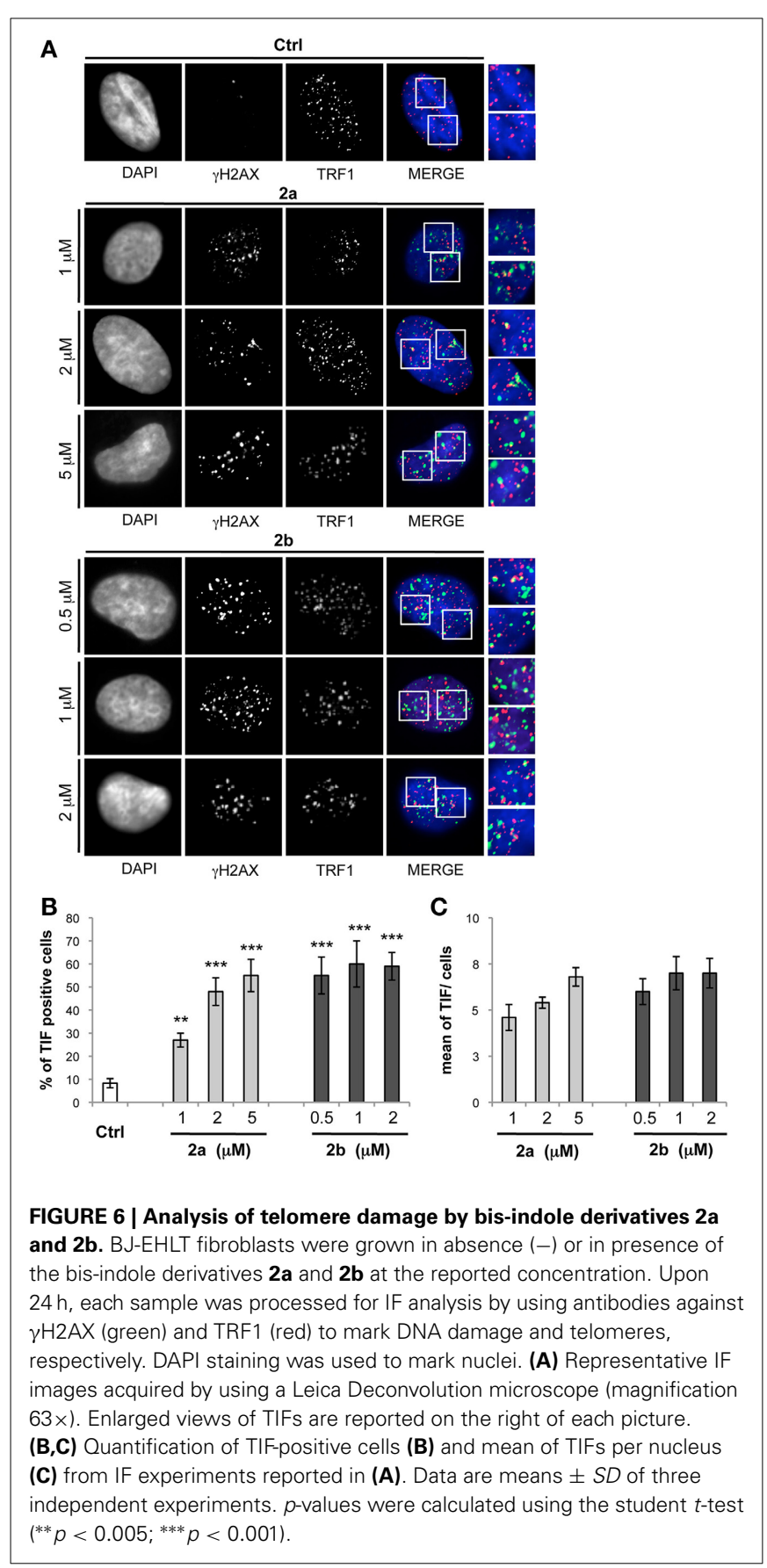

than four $\gamma \mathrm{H} 2 \mathrm{AX} / \mathrm{TRF} 1$ colocalizations (Pearson's correlation coefficient $\geq 0.45$ ), with a mean of about 6 TIFs per nucleus (Figure 6).

Notably, while at the lowest doses of $2 \mathrm{a}$, the majority of $\gamma \mathrm{H} 2 \mathrm{AX}$ spots colocalized with TRF1, at the highest concentrations an important fraction of the damage was not localized at the telomeres. On the contrary, compounds induced both telomeric and not telomeric DNA damage even at low drug doses $(0.5 \mu \mathrm{M}$ concentration). This is in line with recent data in which it has been demonstrated that G-quadruplex structures have been found in the promoters of several genes involved in cancer processes (e.g.,

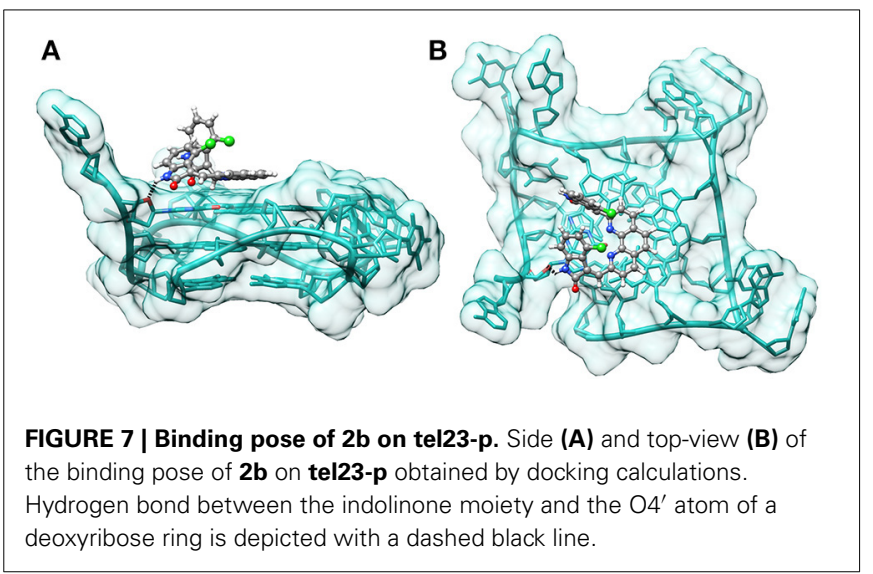

c-myc, bcl-2, VEGF) an now visualized in extra-telomeric regions of human cells (Biffi et al., 2013).

\section{MOLECULAR DOCKING}

In order to understand the mode of binding and the fit of the best ligands $(\mathbf{2} \mathbf{a}, \mathbf{b})$ within the tel23-p G-quadruplex structure (the most stabilized G4) we performed molecular docking calculations. Among computational methods, molecular docking is one of the most important techniques, and it has been widely used to predict or to give insight into the interaction between small ligands and biological macromolecules (such as proteins and nucleic acids). As more and more G4 structures have been determined (Neidle, 2009), a number of novel ligands have been discovered using this technique (Cosconati et al., 2009; Alcaro et al., 2012; Pagano et al., 2012). We docked the ligands to an X-ray crystal structure of the parallel 23-mer human telomeric G4 (PDB ID 3CDM) using AutoDock (Morris et al., 2009). For each ligand, the most favorable complex was selected from the docked structures on the basis of the calculated binding energies. As expected, in both cases, the predicted most favorable binding mode was one where the phenanthroline core is parallel to the plane of the terminal G-tetrad, making extensive $\pi-\pi$ stacking interactions. Noteworthy, in the case of $\mathbf{2} \mathbf{b}$, we observed that the $\mathrm{NH}$ group of one of the indolinone systems is hydrogen bonded to the $\mathrm{O}^{\prime}$ atom of a deoxyribose ring (Figure 7). On the other hand, 2a does not seem capable of forming this additional interaction, probably because of the different spatial arrangement of the indolinone systems, which seem to be involved in an intramolecular lone pair- $\pi$ stacking interaction, conferring rigidity to the molecule (Figure S3, Supplementary Material). This could justify the higher ability of $\mathbf{2 b}$ to increase the thermal stability of the telomeric G4.

\section{CONCLUSIONS}

We have synthesized two bis-indolinone derivatives with the 2,6-disubstituted pyridine core ( $\mathbf{1 a}$ and $\mathbf{1 b}$ ) and two other derivatives having a 1,10-disubstituted phenanthroline core ( $2 \mathbf{a}$ and 2b). These compounds have shown interesting antitumor activity, even if their mode of action is unknown. Interestingly, the structural similarities of these molecules with well-known G-quadruplex binders like for example pyridostatin (Granotier et al., 2005; Rodriguez et al., 2008) or PhenDC3 and PhenDC6 
(Dhamodharan et al., 2012) suggested us that also these molecules could actually bind G-quadruplexes and this interaction maybe responsible of their antitumor activity. Compounds $\mathbf{2} \mathbf{a}$ and $\mathbf{2} \mathbf{b}$ actually are the only two compounds able to selectively stabilize G4 over duplex DNA and also to discriminate among different Gquadruplex structures, having a particular affinity for the parallel human telomeric G-quadruplex tel23-p. Docking calculations have indicated potential binding modes for those compounds, providing possible explanations of the different affinities and activities, and therefore laying the basis for the development of new ligands. All together these results represent the proof of concept that $\mathbf{2 a}$ and $\mathbf{2} \mathbf{b}$ interact and stabilize the G4 structures both in vitro and in cellulo, and therefore that they could be considered as the lead compounds for developing new anticancer drugs.

\section{ACKNOWLEDGEMENT}

This work was supported by the "Italian Association for Cancer Research” (MFAG 11947 and IG 14150).

\section{SUPPLEMENTARY MATERIAL}

The Supplementary Material for this article can be found online at: http://www.frontiersin.org/journal/10.3389/fchem.2014. 00054/abstract

\section{REFERENCES}

Alcaro, S., Costa, G., Distinto, S., Moraca, F., Ortuso, F., Parrotta, L., et al. (2012). The polymorphisms of DNA G-quadruplex investigated by docking experiments with telomestatin enantiomers. Curr. Pharm. Des. 18, 1873-1879. doi: 10.2174/138161212799958495

Andreani, A., Burnelli, S., Granaiola, M., Leoni, A., Locatelli, A., Morigi, R., et al. (2008). Antitumor activity of bis-indole derivatives. J. Med. Chem. 51, 4563-4570. doi: 10.1021/jm800194k

Andreani, A., Burnelli, S., Granaiola, M., Leoni, A., Locatelli, A., Morigi, R., et al. (2010). Antitumor activity and COMPARE analysis of bis-indole derivatives. Bioorg. Med. Chem. 18, 3004-3011. doi: 10.1016/j.bmc.2010.03.063

Biffi, G., Tannahill, D., McCafferty, J., and Balasubramanian, S. (2013). Quantitative visualization of DNA G-quadruplex structures in human cells. Nat. Chem. 5, 182-186. doi: 10.1038/nchem.1548

Bochman, L. N., Paeschke, K., and Zakian, V. A. (2012). DNA secondary structures: stability and function of G-quadruplex structures. Nat. Rev. Gen. 13, 770-780. doi: $10.1038 / \mathrm{nrg} 3296$

Cosconati, S., Marinelli, L., Trotta, R., Virno, A., De Tito, S., Romagnoli, R., et al. (2010). Structural and conformational requisites in DNA quadruplex groove binding: another piece to the puzzle. J. Am. Chem. Soc. 132, 6425-6433. doi: 10.1021/ja1003872

Cosconati, S., Marinelli, L., Trotta, R., Virno, A., Mayol, L., Novellino, E., et al. (2009). Tandem application of virtual screening and NMR experiments in the discovery of brand new DNA quadruplex groove binders. J. Am. Chem. Soc. 131, 16336-16337. doi: 10.1021/ja9063662

Cosconati, S., Rizzo, A., Trotta, R., Pagano, B., Iachettini, S., De Tito, S., et al. (2012). Shooting for selective druglike G-quadruplex binders: evidence for telomeric DNA damage and tumor cell death. J. Med. Chem. 55, 9785-9792. doi: $10.1021 / \mathrm{jm} 301019 \mathrm{w}$

Dai, J., Carver, M., and Yang, D. (2008). Polymorphism of human telomeric quadruplex structures. Biochimie 90, 1172-1183. doi: 10.1016/j.biochi.2008.02.026

Dhamodharan, V., Harikrishna, S., Jagadeeswaran, C., Halder, K., and Pradeepkumar, P. I. (2012). Selective G-quadruplex DNA stabilizing agents based on bisquinolinium and bispyridinium derivatives of 1,8-naphthyridine. J. Org. Chem. 77, 229-242. doi: 10.1021/jo201816g

Di Leva, F. S., Zizza, P., Cingolani, C., D’Angelo, C., Pagano, B., Amato, J., et al. (2013). Exploring the chemical space of G-quadruplex binders: discovery of a novel chemotype targeting the human telomeric sequence. J. Med. Chem. 56, 9646-9654. doi: 10.1021/jm401185b
Fajkus, J., Sýkorová, E., and Leitch, A. R. (2005). Telomeres in evolution and evolution of telomeres. Chromosome Res. 13, 469-479. doi: 10.1007/s10577-0050997-2

Giancola, C., and Pagano, B. (2013). Energetics of ligand binding to Gquadruplexes. Top Curr. Chem. 330, 211-242. doi: 10.1007/128_2012_347

Granotier, C., Pennarun, G., Riou, L., Hoffschir, F., Gauthier, L. R., De Cian, A., et al. (2005). Preferential binding of a G-quadruplex ligand to human chromosome ends. Nucleic Acids Res. 33, 4182-4190. doi: 10.1093/nar/gki722

Granzhan, A., Monchaud, D., Saettel, N., Guédin, A., Mergny, J. L., and TeuladeFichou, M. P. (2010). "One ring to bind them all”-Part II: identification of promising G-quadruplex ligands by screening of cyclophane-type macrocycles. J. Nucleic Acids 2010:460561. doi: 10.4061/2010/460561

Harley, C. B., Futcher, A. B., and Greider, C. W. (1990). Telomeres shorten during ageing of human fibroblasts. Nature 345, 458-460. doi: 10.1038/345458a0

Karsisiotis, A. I., Hessari, N. M., Novellino, E., Spada, G. P., Randazzo, A., and Webba da Silva, M. (2011). Topological characterization of nucleic acid Gquadruplexes by UV absorption and circular dichroism. Angew. Chem. Int. Ed. Engl. 50, 10645-10648. doi: 10.1002/anie.201105193

Kim, N. W. (1997). Clinical implications of telomerase in cancer. Eur. J. Cancer 33, 781-786. doi: 10.1016/S0959-8049(97)00057-9

Kuryavyi, V., Phan, A. T., and Patel, D. J. (2010). Solution structures of all parallelstranded monomeric and dimeric G-quadruplex scaffolds of the human c-kit2 promoter. Nucleic Acids Res. 38, 6757-6773. doi: 10.1093/nar/gkq558

Masiero, S., Trotta, R., Pieraccini, S., De Tito, S., Perone, R., Randazzo, A., et al. (2010). A non-empirical chromophoric interpretation of CD spectra of DNA G-quadruplex structures. Org. Biomol. Chem. 8, 2683-2692. doi: $10.1039 / \mathrm{c} 003428 \mathrm{~b}$

Monchaud, D., Granzhan, A., Saettel, N., Guédin, A., Mergny, J. L., and TeuladeFichou, M. P. (2010). "One ring to bind them all"-part I: the efficiency of the macrocyclic scaffold for G-quadruplex DNA recognition. J. Nucleic Acids 2010:525862. doi: 10.4061/2010/525862

Morris, G. M., Huey, R., Lindstrom, W., Sanner, M. F., Belew, R. K., Goodsell, D. S., et al. (2009). AutoDock4 and AutoDockTools4: automated docking with selective receptor flexibility. J. Comput. Chem. 30, 2785-2791. doi: 10.1002/jcc.21256.

Neidle, S. (2009). The structures of quadruplex nucleic acids and their drug complexes. Curr. Opin. Struct. Biol. 19, 239-250. doi: 10.1016/j.sbi.2009.04.001

Ohnmacht, S. A., and Neidle, S. (2014). Small-molecule quadruplextargeted drug discovery. Bioorg. Med. Chem. Lett. 24, 2602-2612. doi: 10.1016/j.bmcl.2014.04.029

Pagano, B., Cosconati, S., Gabelica, V., Petraccone, L., De Tito, S., Marinelli, L., et al. (2012). State-of-the-art methodologies for the discovery and characterization of DNA G-quadruplex binders. Curr. Pharm. Des. 18, 1880-1899. doi: $10.2174 / 138161212799958332$

Pagano, B., Fotticchia, I., De Tito, S., Mattia, C. A., Mayol, L., Novellino, E., et al. (2010). Selective binding of distamycin a derivative to G-quadruplex structure [d(TGGGGT)] 4 . J. Nucleic Acids 2010:247137. doi: 10.4061/2010/247137

Parkinson, G. N., Cuenca, F., and Neidle, S. (2008). Topology conservation and loop flexibility in quadruplex-drug recognition: crystal structures of inter- and intramolecular telomeric DNA quadruplex-drug complexes. J. Mol. Biol. 381, 1145-1156. doi: 10.1016/j.jmb.2008.06.022.

Petraccone, L., Fotticchia, I., Cummaro, A., Pagano, B., Ginnari-Satriani, L., Haider, S., et al. (2011). The triazatruxene derivative azatrux binds to the parallel form of the human telomeric G-quadruplex under molecular crowding conditions: biophysical and molecular modeling studies. Biochimie 93, 1318-1327. doi: 10.1016/j.biochi.2011.05.017

Phan, A. T., Kuryavyi, V., Burge, S., Neidle, S., and Patel, D. P. (2007). Structure of an unprecedented G-quadruplex scaffold in the human c-kit promoter. J. Am. Chem. Soc. 129, 4386-4392. doi: 10.1021/ja068739h

Price, C. M. (1999). Telomeres and telomerase: broad effects on cell growth. Curr Opin. Genet. Dev. 9, 218-224. doi: 10.1016/S0959-437X(99)80032-X

Randazzo, A., Spada, G. P., and Webba da Silva, M. (2013). Circular dichroism of quadruplex structures. Top. Curr. Chem. 330, 67-86. doi: $10.1007 / 128 \_2012 \quad 331$

Renciuk, D., Kejnovska, I., Skolakova, P., Bednarova, K., Motlova, J., and Vorlickova, M. (2009). Arrangements of human telomere DNA quadruplex in physiologically relevant $\mathrm{K}^{+}$solutions. Nucleic Acids Res. 37, 6625-6634. doi: 10.1093/nar/gkp701

Rodriguez, R., Muller, S., Yeoman, J. A., Trentesaux, C., Riou, J.-F., and Balasubramanian, S. (2008). A novel small molecule that alters shelterin 
integrity and triggers a DNA-damage response at telomeres. J. Am. Chem. Soc. 130, 15758-15759. doi: 10.1021/ja805615w

Salvati, E., Leonetti, C., Rizzo, A., Scarsella, M., Mottolese, M., Galati, R., et al. (2007). Telomere damage induced by the G-quadruplex ligand RHPS4 has an antitumor effect. J. Clin. Invest. 117, 3236-3247. doi: 10.1172/JCI32461

Salvati, E., Scarsella, M., Porru, M., Rizzo, A., Iachettini, S., Tentori, L., et al. (2010). PARP1 activated at telomeres upon G4 stabilization: possible target for telomere-based therapy. Oncogene 29, 6280-6293. doi: 10.1038/onc.2010.344

Shay, J. W., and Wright, W. E. (2005). Senescence and immortalization: role of telomeres and telomerase. Carcinogenesis 26, 867-874. doi 10.1093/carcin/bgh296

Sun, D., Thompson, B., Cathers, B. E., Salazar, M., Kerwin, S. M., Trent, J. O., et al. (1997). Inhibition of human telomerase by a G-quadruplex-interactive compound. J. Med. Chem. 40, 2113-2116. doi: 10.1021/jm970199z

Takai, H., Smogorzewska, A., and de Lange, T. (2003). DNA damage foci at dysfunctional telomeres. Curr. Biol. 13, 1549-1556. doi: 10.1016/S0960-9822(03) 00542-6

Thiriet, C., and Hayes, J. J. (2005). Chromatin in need of a fix: phosphorylation of H2AX connects chromatin to DNA repair. Mol. Cell 18, 617-622. doi 10.1016/j.molcel.2005.05.008

Wright, W. E., Tesmer, V. M., Huffman, K. E., Levene, S. D., and Shay, J. W. (1997). Normal human chromosomes have long G-rich telomeric overhangs at one end. Genes Dev. 11, 2801-2809. doi: 10.1101/gad.11.21.2801
Zahler, A. M., Williamson, J. R., Cech, T. R., and Prescott, D. M. (1991). Inhibition of telomerase by G-quartet DNA structures. Nature 350, 718-720. doi: $10.1038 / 350718 \mathrm{a} 0$

Conflict of Interest Statement: The authors declare that the research was conducted in the absence of any commercial or financial relationships that could be construed as a potential conflict of interest.

Received: 03 June 2014; paper pending published: 17 June 2014; accepted: 04 July 2014; published online: 24 July 2014.

Citation: Amato J, Iaccarino N, Pagano B, Morigi R, Locatelli A, Leoni A, Rambaldi M, Zizza P, Biroccio A, Novellino E and Randazzo A (2014) Bis-indole derivatives with antitumor activity turn out to be specific ligands of human telomeric G-quadruplex. Front. Chem. 2:54. doi: 10.3389/fchem.2014.00054

This article was submitted to Medicinal and Pharmaceutical Chemistry, a section of the journal Frontiers in Chemistry.

Copyright () 2014 Amato, Iaccarino, Pagano, Morigi, Locatelli, Leoni, Rambaldi, Zizza, Biroccio, Novellino and Randazzo. This is an open-access article distributed under the terms of the Creative Commons Attribution License (CC BY). The use, distribution or reproduction in other forums is permitted, provided the original author $(s)$ or licensor are credited and that the original publication in this journal is cited, in accordance with accepted academic practice. No use, distribution or reproduction is permitted which does not comply with these terms. 